ASTHMA

\title{
Asthma and atopy in overweight children
}

\author{
L M Schachter, J K Peat, C M Salome
}

Thorax 2003;58:1031-1035

Background: Obesity may be associated with an increase in asthma and atopy in children. If so, the effect could be due to an effect of obesity on lung volume and thus airway hyperresponsiveness.

Methods: Data from 5993 caucasian children aged 7-12 years from seven epidemiological studies performed in NSW were analysed. Subjects were included if data were available for height, weight, age, skin prick test results to a common panel of aeroallergens, and a measure of airway responsiveness. History of doctor diagnosed asthma, wheeze, cough, and medication use was obtained by questionnaire. Recent asthma was defined as a doctor diagnosis of asthma ever and wheeze in the last 12 months. Body mass index (BMI) percentiles, divided into quintiles per year age, were used as a measure of standardised weight. Dose response ratio (DRR) was used as a measure of airway responsiveness. Airway hyperresponsiveness was defined as a DRR of $\geqslant 8$.1. Adjusted odds ratios were obtained by logistic regression.

See end of article for authors' affiliations

Correspondence to: Dr L Schachter, Department of 'Respiratory Medicine, Austin and Repatriation Medical Centre, Studley Road Heidelberg, VIC 3084 Australia; indams@ bigpond.com
Results: After adjusting for atopy, sex, age, smoking and family history, BMI was a significant risk factor for wheeze ever $(O R=1.06, p=0.007)$ and cough $(O R=1.08, p=0.001)$, but not for recent asthma $(O R=1.02, p=0.43)$ or airway hyperresponsiveness $(O R=0.97 p=0.17)$. In girls a higher $B M l$ was significantly associated with higher prevalence of atopy $\left(\chi^{2}\right.$ trend $\left.7.9, p=0.005\right)$, wheeze ever $\left(\chi^{2}\right.$ trend $10.4, p=0.001)$, and cough $\left(\chi^{2}\right.$ trend 12.3, $\left.p<0.001\right)$. These were not significant in boys.

Conclusions: Higher BMI is a risk factor for atopy, wheeze ever, and cough in girls only. Higher BMI is not a risk factor for asthma or airway hyperresponsiveness in either boys or girls. lintsing $\mathrm{n}$ the past two decades there has been a significant increase in the prevalence of asthma, atopy, and obesity in children worldwide. ${ }^{1}$ It is possible that these events are linked. ${ }^{2-4}$ In adults, large random population studies have shown an increase in the incidence ${ }^{5}$ and prevalence ${ }^{6}$ of wheezing and diagnosed asthma in obese subjects. Furthermore, in randomised controlled trials, weight loss has been associated with improvements in asthma symptoms and peak expiratory flow rate (PEFR)..$^{7}$ While these findings strongly suggest that obesity is associated with an increase in asthma-like symptoms, it has not be established that this is due to an increase in the prevalence of asthma in obese subjects. We have shown previously that adults with severe obesity reported more wheeze and shortness of breath but that this was not associated with a higher prevalence of atopy, airway hyperresponsiveness, or airway obstruction, suggesting that the prevalence of asthma is not higher in this group. ${ }^{6}$ Other studies have shown an increase in airway responsiveness in men' and adolescent girls, ${ }^{3}$ but these results have not been consistent.

In children, cross sectional studies of large random population samples have also shown that excess body weight is associated with a higher rate of both symptoms and diagnosed asthma. ${ }^{2}{ }^{10}$ However, in Taiwanese teenagers obesity was associated with an increase in airway hyperresponsiveness, atopy, and atopic symptoms in girls but not boys. $^{3}$ This suggests that the association between asthma and excess body weight may differ between adults and children and between boys and girls.

The association between obesity and atopy has also rarely been explored. It is possible that obesity could cause atopy or inflammation or that there is some common factor that predisposes to both obesity and atopy. The results from previous studies tend to be confusing, with one study showing that obesity was associated with an increase in atopy in girls but not in boys, ${ }^{3}$ while another study showed no association with atopy, allergic symptoms, or IgE levels in more than 15000 young adults. ${ }^{11}$
In this paper we report an analysis of cross sectional data in a large population of caucasian Australian children. The aim was to determine if increased body weight, as measured by body mass index, is associated with a higher prevalence of asthma or atopy or with an increase in airway obstruction or airway responsiveness to histamine. We also examined whether the association between body weight, atopy, and symptoms of asthma was different between girls and boys.

\section{METHODS}

Data from seven large epidemiological studies of children aged 7-12 years conducted in seven regions of NSW, Australia between 1991 and 1993 were pooled. Details of the populations, response rates, and non-responders have been published elsewhere. ${ }^{12}{ }^{13}$ Data from less than 5\% of children who were non-caucasian were excluded. Children for whom height, weight, age, and airway responsiveness were measured were included.

Information on symptoms, family history, and diagnoses were collected by a parent completed questionnaire. ${ }^{14}$ Recent wheeze was defined as the presence of wheeze in the previous 12 months. Recent asthma was defined as recent wheeze plus a doctor diagnosis of asthma ever.

Lung function was recorded before and after saline inhalation using Mijnhardt VRS dry rolling seal spirometers (Mijnhardt BV, Bunnik, The Netherlands) and Scientific and Medical (S\&M) data acquisition software. Forced expiratory manoeuvres were repeated until two measurements of forced expiratory volume in 1 second $\left(\mathrm{FEV}_{1}\right)$ within $100 \mathrm{ml}$ were obtained. The largest $\mathrm{FEV}_{1}$ was used in the analyses. Children were tested after withholding $\beta$ agonist for at least 6 hours. Percentage predicted $\mathrm{FEV}_{1}$, forced vital capacity (FVC), and PEFR were calculated. ${ }^{15}$

Airway responsiveness was measured by the rapid histamine inhalation test. ${ }^{16}$ The dose of histamine that caused a $20 \%$ fall in $\mathrm{FEV}_{1}\left(\mathrm{PD}_{20} \mathrm{FEV}_{1}\right)$ and the dose response ratio (DRR; percentage change in final $\mathrm{FEV}_{1}$ from baseline divided by the total dose of histamine administered) were calculated. 
Because many children had an $\mathrm{FEV}_{\mathrm{I}}$ that remained stable or improved slightly during the study, a constant of 3 was added to all DRR values to return a positive value for logarithmic conversion. Participants with a fall in $\mathrm{FEV}_{1}$ of $20 \%$ or more at $\leqslant 3.9 \mu \mathrm{mol}$ histamine were defined as having airway hyperresponsiveness, which is equivalent to a DRR of $>8.1$.

BMI was calculated by dividing weight $(\mathrm{kg})$ by the square of the height $(\mathrm{m})\left(\mathrm{kg} / \mathrm{m}^{2}\right)$. There is no standard for weight distribution in children so we used BMI percentiles per sex per age as a measure of standardised weight. ${ }^{17}{ }^{18}$ NHANES I was used as the reference population for the BMI percentiles $^{19}$ as there are no reference data available for Australian children. No studies have compared distribution of overweight and obese Australian children in this age group with those in the USA. We present results as BMI percentiles corrected for age and sex. BMI percentiles divided into quintiles were used to assess the relationship between standardised weight, symptoms, and lung function. Analyses were also performed with BMI as a continuous variable and divided into overweight (BMI 85-95th percentile) and obese (BMI $>95$ th percentile).

\section{Statistical analysis}

Data were analysed using the statistical package SPSS (Chicago, IL). Geometric mean values are reported for DRR values, which were converted to base 10 logarithms before analysis. For all analyses p values of $<0.05$ were regarded as significant. Pearson's chi square $\left(\chi^{2}\right)$ statistic and chi square trend were used to determine the significance of differences in prevalence between different BMI groups.

Logistic regression was used to compute odds ratio for outcomes in the presence of higher BMI and adjusted for family history of asthma, age, sex, atopy status, and exposure to cigarette smoke. Partial correlation and logistic regression was used to assess correlation between BMI and airway responsiveness adjusting for airway size using $\mathrm{FVC} \%$ predicted and $\mathrm{FEV}_{1} / \mathrm{FVC}^{20}{ }^{20}$

Linear regression was used to assess the relation between lung function and BMI percentile. One way ANOVA was used to analyse means of grouped data with Duncan's post hoc test to limit the number of multiple comparisons.

Tests for homogeneity were performed (Meta-view in Review Manager (RevMan), Version 4.2, Update Software) between the seven regions for the prevalence of wheeze, cough and airway hyperresponsiveness.

\section{RESULTS}

Complete data were available for 5993 children. The response rates were: Belmont $82.7 \%$, Lismore $76.8 \%$, Sydney $76.8 \%$, Western Sydney $75.9 \%$, Moree $74.2 \%$, Wagga Wagga $82.7 \%$, and Broken Hill $80 \%$. The proportion of participants in each group, classified according to quintiles of BMI percentile, is shown in table 1. Tests for homogeneity were performed between the seven regions and there were no significant differences in the prevalence of wheeze $\left(\chi^{2}=8.42, p=0.21\right)$, cough $\left(\chi^{2}=2.99, \mathrm{p}=0.81\right)$, or airway hyperresponsiveness $\left(\chi^{2}=4.33, \mathrm{p}=0.63\right)$.

Table 1 shows that a higher BMI was associated with a higher prevalence of atopy in girls but not boys. There was no significant association with family history of asthma for either girls or boys. Exposure to cigarette smoke had a highly significant association with a higher BMI in both girls and boys.

In separate analyses of data from girls and boys (table 2), a higher BMI was significantly associated with a higher prevalence of atopy, wheeze in the last 12 months, wheeze ever, cough, and the use of medication for asthma in girls but not in boys. However, there was no significant association between BMI and the prevalence of diagnosed asthma or recent asthma in either boys or girls. The association between higher BMI and cough was significant in both atopic and non-atopic boys and girls (fig 1).

After adjusting for atopy, family history of asthma and exposure to cigarette smoke, a higher BMI was associated with a higher prevalence of wheeze ever, cough, and medication use for asthma (table 3). However, there was no significant association between a higher BMI and the prevalence of diagnosed asthma, recent asthma, or airway hyperresponsiveness (table 3 ).

Table 4 shows spirometric function and airway responsiveness for girls and boys in each of the BMI quintiles. For all spirometric variables, mean values were within the predicted normal range for all of the BMI groups. In both girls and boys there were significant differences between BMI quintiles in $\mathrm{FEV}_{1} \%$ predicted and FVC \% predicted. Post hoc comparison showed that $\mathrm{FEV}_{1} \%$ predicted and $\mathrm{FVC} \%$

Table 1 Characteristics of subjects included in the study

\begin{tabular}{|c|c|c|c|c|c|c|}
\hline & BMI quintile 1 & BMI quintile 2 & BMI quintile 3 & BMI quintile 4 & BMI quintile 5 & $\begin{array}{l}p \text { value } \\
\text { for trend }\end{array}$ \\
\hline \multicolumn{7}{|l|}{ Total no } \\
\hline Boys & 584 & 630 & 619 & 611 & 563 & \\
\hline Girls & 589 & 595 & 569 & 598 & 625 & \\
\hline \multicolumn{7}{|c|}{ Mean $(95 \% \mathrm{Cl}) \mathrm{BMI}$} \\
\hline Boys & 14.6 (14.5 to 14.7$)$ & $15.8(15.8$ to 15.8$)$ & 16.7 (16.6 to 16.7$)$ & $18.0(17.9$ to 18.1$)$ & 21.7 (21.4 to 21.9 ) & $<0.001$ \\
\hline Girls & 14.5 (14.4 to 14.6$)$ & $15.9(15.9$ to 16.0$)$ & $17.2(17.1$ to 17.2$)$ & $18.9(18.8$ to 18.9$)$ & $22.3(22.1$ to 22.5$)$ & $<0.001$ \\
\hline \multicolumn{7}{|c|}{ Mean $(95 \% \mathrm{Cl})$ height $(\mathrm{cm})$} \\
\hline Boys & $136.7(136.1$ to 137.2$)$ & $136.3(135.7$ to 136.8$)$ & $137.4(136.9$ to 138.0$)$ & $138.4(137.9$ to 139.0$)$ & 140.7 (140.0 to 141.3$)$ & $<0.001$ \\
\hline Girls & $135.6(135.0$ to 136.2$)$ & $135.8(135.2$ to 136.5$)$ & $137.1(136.5$ to 137.7$)$ & $139.0(138.4$ to 139.6$)$ & $140.3(139.6$ to 140.9$)$ & $<0.001$ \\
\hline \multicolumn{7}{|c|}{ Mean $(95 \% \mathrm{Cl})$ age (years) } \\
\hline Boys & 9.95 (9.88 to 10.03$)$ & $9.68(9.61$ to 9.76$)$ & 9.71 (9.63 to 9.79$)$ & 9.77 (9.70 to 9.84$)$ & 9.81 (9.73 to 9.88$)$ & $<0.001$ \\
\hline Girls & $9.80(9.73$ to 9.88$)$ & $9.68(9.60$ to 9.75$)$ & $9.77(9.70$ to 9.84$)$ & $9.83(9.76$ to 9.91$)$ & $9.70(9.62$ to 9.77$)$ & 0.01 \\
\hline \multicolumn{7}{|c|}{ Mean $(95 \% \mathrm{Cl})$ prevalence of atopy* $(\%)$} \\
\hline Boys & 48.2 (44.2 to 52.3 ) & $41.8(38.0$ to 45.7$)$ & 44.4 (40.5 to 48.3$)$ & 43.9 (40.0 to 47.8$)$ & 45.2 (41.1 to 49.3$)$ & 0.56 \\
\hline Girls & $31.4(27.7$ to 35.2$)$ & $33.7(29.9$ to 37.5$)$ & $33.1(29.2$ to 37.0$)$ & $37.3(33.5$ to 41.1$)$ & 38.5 (34.7 to 42.3$)$ & 0.004 \\
\hline \multicolumn{7}{|c|}{ Mean $(95 \% \mathrm{Cl})$ prevalence of family history of asthma** $(\%)$} \\
\hline Boys & $24.9(21.4$ to 28.4$)$ & $29.8(26.2$ to 33.4$)$ & 30.3 (26.7 to 33.9 ) & 25.9 (22.4 to 29.4$)$ & $28.9(25.2$ to 32.6$)$ & 0.52 \\
\hline Girls & $27.0(23.4$ to 30.6$)$ & $25.8(22.3$ to 29.3$)$ & $27.7(24.0$ to 31.4$)$ & 29.7 (26.0 to 33.4$)$ & $28.1(24.6$ to 31.6$)$ & 0.29 \\
\hline \multicolumn{7}{|c|}{ Mean $(95 \% \mathrm{Cl})$ prevalence of smoker in family** $(\%)$} \\
\hline Boys & $29.9(26.2$ to 33.6$)$ & $31.8(28.2$ to 35.4$)$ & 31.0 (27.4 to 34.6$)$ & 34.4 (30.6 to 38.2 ) & 39.7 (35.7 to 43.7 ) & $<0.001$ \\
\hline Girls & 32.4 (28.6 to 36.2$)$ & $33.2(29.4$ to 37.0$)$ & $33.1(29.2$ to 37.0$)$ & $34.3(30.5$ to 38.1$)$ & 42.7 (38.8 to 46.6$)$ & $<0.001$ \\
\hline
\end{tabular}


Table 2 Symptoms according to BMI quintile

\begin{tabular}{|c|c|c|c|c|c|c|}
\hline & BMI quintile 1 & BMI quintile 2 & BMI quintile 3 & BMI quintile 4 & BMI quintile 5 & $\begin{array}{l}p \text { value for } \\
\text { trend }\end{array}$ \\
\hline \multicolumn{7}{|c|}{ Wheeze in last 12 months } \\
\hline Boys & 26.9 (23.3 to 30.5 ) & 23.6 (20.3 to 26.9$)$ & 25.7 (22.3 to 29.1$)$ & $25.5(22.0$ to 29.0$)$ & 28.7 (25.0 to 32.4 ) & 0.33 \\
\hline Girls & $19.2(16.0$ to 22.4$)$ & 22.9 (19.5 to 26.3$)$ & $22.2(18.8$ to 25.6$)$ & $22.6(19.3$ to 26.0$)$ & 25.1 (21.7 to 28.5$)$ & 0.03 \\
\hline \multicolumn{7}{|c|}{ 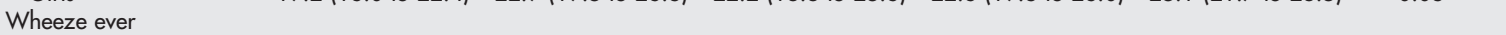 } \\
\hline Boys & 40.5 (36.5 to 44.5$)$ & 41.0 (37.2 to 44.8 ) & 40.3 (36.4 to 44.2 ) & $45.6(41.7$ to 49.6$)$ & 43.6 (39.5 to 47.7$)$ & 0.09 \\
\hline Girls & $29.9(26.2$ to 33.6$)$ & 33.7 (29.9 to 37.5$)$ & $33.6(29.7$ to 37.5$)$ & $34.2(30.4$ to 38.0$)$ & $39.4(35.6$ to 43.2$)$ & 0.001 \\
\hline \multicolumn{7}{|c|}{ Cough in last 12 months } \\
\hline Boys & $20.3(17.0$ to 23.6$)$ & $21.3(18.1$ to 24.5$)$ & 19.4 (16.3 to 22.5$)$ & $23.9(20.5$ to 27.3$)$ & 24.4 (20.9 to 28.0$)$ & 0.06 \\
\hline Girls & $19.3(16.1$ to 22.5$)$ & $17.4(14.4$ to 20.5$)$ & $22.7(19.3$ to 26.1$)$ & $23.7(20.3$ to 27.1$)$ & $26.5(23.0$ to 30.0$)$ & 0.006 \\
\hline \multicolumn{7}{|c|}{ 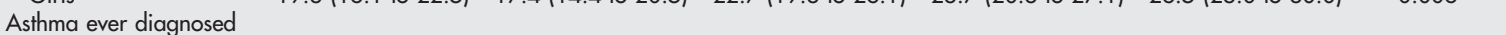 } \\
\hline Boys & $32.6(28.8$ to 36.4$)$ & 34.1 (30.4 to 37.8 ) & 33.8 (30.1 to 37.5$)$ & $35.6(31.8$ to 39.4$)$ & 34.9 (31.0 to 38.8 ) & 0.32 \\
\hline Girls & 25.5 (22.0 to 29.0$)$ & $23.6(20.2$ to 27.0$)$ & 26.7 (23.1 to 30.3$)$ & $27.3(23.7$ to 30.9$)$ & $28.9(25.4$ to 32.5$)$ & 0.065 \\
\hline \multicolumn{7}{|c|}{ 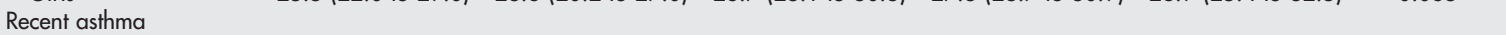 } \\
\hline Boys & 20.2 (16.9 to 23.5$)$ & 17.6 (14.6 to 20.6$)$ & $19.2(16.1$ to 22.3$)$ & 18.8 (15.7 to 21.9$)$ & 21.1 (17.7 to 24.5$)$ & 0.56 \\
\hline Girls & $13.6(10.8$ to 16.4$)$ & $14.1(11.3$ to 16.9$)$ & $15.1(12.2$ to 18.0$)$ & $15.1(12.2$ to 18.0$)$ & 16.5 (13.6 to 19.4$)$ & 0.14 \\
\hline \multicolumn{7}{|c|}{ Medication use in last 12 months } \\
\hline Boys & $27.2(23.6$ to 30.8$)$ & $25.8(22.4$ to 29.2$)$ & $26.4(22.9$ to 29.9$)$ & $27.0(23.5$ to 30.5$)$ & $31.9(28.1$ to 35.8$)$ & 0.13 \\
\hline Girls & $19.2(16.0$ to 22.4$)$ & $22.1(18.8$ to 25.4$)$ & $21.0(17.7$ to 24.4$)$ & $24.6(21.2$ to 28.1$)$ & $25.2(21.8$ to 28.6$)$ & 0.02 \\
\hline
\end{tabular}

predicted were significantly reduced in the lowest quintile compared with the rest of the population measured. However, there were no differences in $\mathrm{FEV}_{\mathrm{l}} / \mathrm{FVC}$ ratio, suggesting that low BMI was not associated with an increase in airway obstruction in girls or boys. This observation was supported in boys by the finding that there was also no difference between BMI quintiles in flow rates as measured by $\mathrm{PEF} \%$ predicted or $\mathrm{FEF}_{25-75} \%$ predicted. However, in girls there was a significant reduction in PEF \% predicted and $\mathrm{FEF}_{25-75} \%$ predicted between the lowest BMI quintile compared with the highest quintile. There was no significant association between BMI and either the prevalence of airway hyperresponsiveness or the severity of airway responsiveness, measured by DRR, in either boys or girls. This remained true after adjusting DRR for airway size using FVC \% predicted and $\mathrm{FEV}_{\mathrm{l}} / \mathrm{FVC} \%$ (standardised coefficient $\beta=-0.002$, $\mathrm{p}=0.89)^{20}$

All analyses were repeated using BMI as a continuous variable, or with children categorised as normal (BMI $<85$ th percentile), overweight (BMI 85-95th percentile), or obese (BMI $>95$ th percentile). ${ }^{21-23}$ The results of these analyses did not differ from the original analyses.

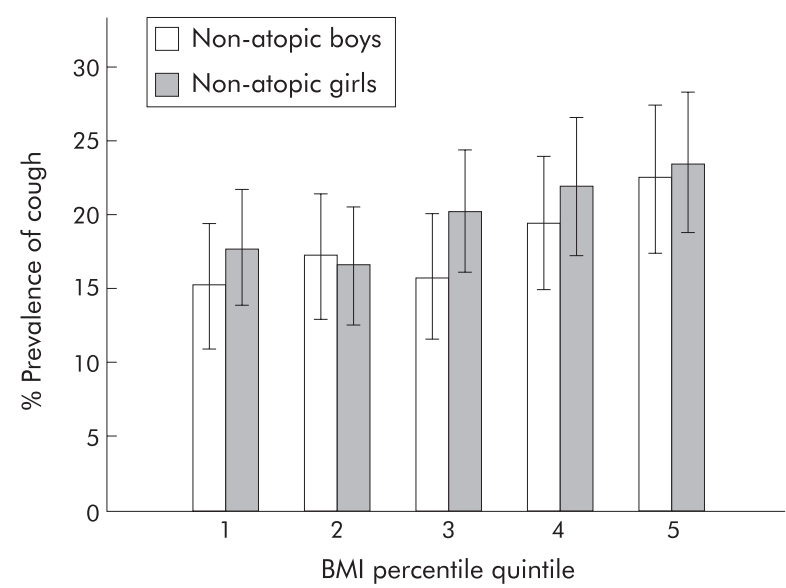

Figure 1 Prevalence of cough in the last 12 months in non-atopic girls and boys by BMI quintile. There was a significant increase in the presence of cough with higher BMI quintile in both non-atopic girls $(p=0.02)$ and boys $(p=0.02)$.

\section{DISCUSSION}

This study confirms the findings of previous studies that a higher BMI is associated with a higher prevalence of symptoms of wheeze and cough in children. This association was stronger in girls than in boys. However, the association was independent of atopic status and there was no association between higher BMI and the presence of either airway obstruction or airway hyperresponsiveness. Neither diagnosed asthma nor the combination of diagnosed asthma and recent symptoms were associated with higher body weight.

These findings suggest that a higher BMI in children is associated with a higher prevalence of symptoms that are often attributed to asthma, but not with a higher prevalence of asthma. We found that a higher BMI in children was not associated with a higher prevalence of diagnosis of asthma, but was associated with a higher prevalence of atopy in girls but not in boys.

The distribution of BMI in these samples is similar to the general population in Australia. ${ }^{24}$ The methods and the IUATLD questionnaire were similar to those used in other large epidemiological studies and were well validated. ${ }^{14}$

This study has several potential limitations inherent in a large cross sectional group of children from seven different regions across New South Wales. Also, BMI percentiles were calculated from USA data as this information is not available currently for Australia. This is unlikely to have invalidated the study outcomes, since the trend for the increase in obesity in children in Australia is closely following the USA trend. ${ }^{24}$ Although BMI may not be the best measure of obesity in children, it is widely used and we do not have other information on which to base an alternative definition. ${ }^{17}$

The association between a higher BMI and symptoms of wheeze and cough in children has been observed in previous studies. $^{56}$ However, wheeze and cough are non-specific symptoms which may be attributed to a number of different causes, including asthma. To confirm a diagnosis of asthma in children presenting with a history of wheeze or cough, it would usually be necessary to find evidence of variable airway obstruction. In this population the increased prevalence of wheeze and cough associated with increased BMI was not associated with any higher prevalence of airway obstruction or airway hyperresponsiveness. This suggests that the excess symptoms among overweight children may be due to causes other than asthma. Increased BMI is associated with an increase in the occurrence of both gastro-oesophageal reflux ${ }^{25}$ and sleep apnoea, ${ }^{26}$ and both of these conditions 
Table 3 Adjusted odds ratio for symptoms and airway hyperresponsiveness in comparison with the normal weight group

\begin{tabular}{lllll}
\hline & BMI percentile & & BMI percentile & \\
& 85-95 & p value & 95-100 & p value \\
\hline Wheeze in last 12 months & $1.12(0.85$ to 1.46$)$ & 0.42 & $1.34(0.98$ to 1.83$)$ & 0.07 \\
Wheeze ever & $1.23(0.97$ to 1.55$)$ & 0.08 & $1.26(1.01$ to 1.56$)$ & 0.04 \\
Recent asthma & $1.15(0.85$ to 1.56$)$ & 0.37 & $0.95(0.67$ to 1.35$)$ & 0.95 \\
Diagnosed asthma & $1.10(0.86$ to 1.42$)$ & 0.45 & $0.87(0.65$ to 1.17$)$ & 0.36 \\
Cough in the last 12 months & $1.26(0.97$ to 1.63$)$ & 0.09 & $1.40(1.05$ to 1.87$)$ & 0.02 \\
Dry cough & $1.16(0.91$ to 1.47$)$ & 0.24 & $1.36(1.05$ to 1.77$)$ & 0.02 \\
Medication usage for asthma ever & $1.35(1.01$ to 1.72$)$ & 0.02 & $0.90(0.68$ to 1.20$)$ & 0.47 \\
Medication usage for asthma in last & $1.09(0.84$ to 1.48$)$ & 0.57 & $1.06(0.73$ to 1.54$)$ & 0.75 \\
12 months & & & & \\
Airway hyperresponsiveness & $0.84(0.62$ to 1.14$)$ & 0.27 & $0.85(0.61$ to 1.20$)$ & 0.85 \\
\hline
\end{tabular}

Odds ratios were calculated correcting for sex, atopy status, family history of asthma, and family smoking history. The results are reported as adjusted odds ratios with $95 \%$ confidence intervals.

may be a cause of symptoms of wheeze or cough without changes in lung function or airway responsiveness.

Alternatively, increased BMI may be associated with a number of changes to the mechanical function of the lungs and airways that could lead to symptoms of wheeze and cough. Other studies have shown that a higher BMI is associated with a higher rate of wheeze with exercise. ${ }^{10}$ In this study we did not collect information that allowed us to differentiate between wheeze at rest and wheeze with exertion, so we cannot determine the extent to which the excess wheezing in our overweight subjects was due to wheeze during exercise. Exertional wheeze in overweight subjects may be due to an increase in the work of breathing, with upper airway collapse or changes in lung mechanics increasing the load on the upper airway. Other studies have shown an increase in airway resistance in obese subjects, ${ }^{27}$ and wheeze may be due to changes in airway calibre, collapsibility, or inability to overcome airway hysteresis.

Changes in compliance or elastic recoil resulting from low lung volume could decrease the tidal fluctuations of airway smooth muscle and enhance contractility, ${ }^{28}$ and thus shift the dose response curve or increase the level of the maximal response. ${ }^{29}$ We found no evidence of lower flow rates or higher airway hyperresponsiveness in the highest quintile.
Although we have shown previously that FVC is reduced in obese adults, ${ }^{6}$ we did not find a significant reduction in FVC in children in the highest BMI quintile. We did not measure lung volumes and therefore it is not clear whether the effects of obesity on lung volume are not as prevalent in children as in adults or are less prominent if a higher body weight is present before puberty. Further studies are required to look at lung volumes in obese children and changes with puberty.

Although inhaled corticosteroid medication can normalise lung function and airway responsiveness, ${ }^{30}$ it is unlikely that the use of such medication could account for the absence of any association between a higher BMI and increased airway obstruction or airway hyperresponsiveness since there was only a slight trend to a higher rate of medication use with higher weight. Furthermore, it is unlikely that symptoms would persist during inhaled corticosteroid medication treatment if airway hyperresponsiveness or airway obstruction had been normalised.

A previous study found that increased BMI is associated with a higher prevalence of atopy and symptoms of wheeze in girls but not in boys, which our study confirms. ${ }^{3}$ The cause for this is unknown and may relate to differences in hormonal levels, inflammatory markers, or body fat distribution. A correlation between BMI and airway hyperresponsiveness

Table 4 Lung function according to BMl quintile

\begin{tabular}{|c|c|c|c|c|c|c|}
\hline & BMI quintile 1 & BMI quintile 2 & BMI quintile 3 & BMI quintile 4 & BMI quintile 5 & $\begin{array}{l}\mathrm{p} \text { value for } \\
\text { trend }\end{array}$ \\
\hline \multicolumn{7}{|c|}{$\mathrm{FEV}_{1}(\% \text { predicted })^{*}$} \\
\hline Boys & $101.9(101.0$ to 102.8$)$ & 104.3 (103.4 to 105.2$)$ & $105.6(104.7$ to 106.5$)$ & 105.4 (104.4 to 106.3$)$ & $106.1(105.2$ to 107.0$)$ & $<0.01$ \\
\hline Girls & 106.7 (105.7 to 107.7$)$ & 109.3 (108.3 to 110.3$)$ & 109.5 (108.5 to 110.4$)$ & 110.4 (109.4 to 111.4$)$ & 111.0 (110.0 to 112.1$)$ & $<0.01$ \\
\hline \multicolumn{7}{|c|}{ FVC (\% predicted)* } \\
\hline Boys & $98.5(97.7$ to 99.4$)$ & 101.8 (100.9 to 102.7$)$ & 103.1 (102.1 to 104.0$)$ & $103.3(102.4$ to 104.2$)$ & $104.2(103.2$ to 105.1$)$ & $<0.01$ \\
\hline Girls & $102.0(101.2$ to 102.8$)$ & 104.7 (103.9 to 110.3$)$ & 105.5 (104.6 to 106.4$)$ & $107.2(106.3$ to 108.1$)$ & $107.4(106.5$ to 108.3$)$ & $<0.01$ \\
\hline \multicolumn{7}{|c|}{ 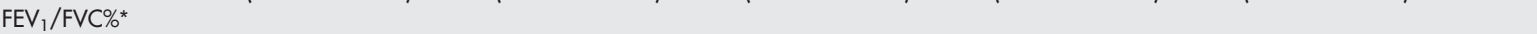 } \\
\hline Boys & $90.7(90.2$ to 91.1$)$ & 89.7 (89.2 to 90.2 ) & $89.8(89.3$ to 90.2$)$ & 89.2 (88.7 to 89.6 ) & 89.0 (88.5 to 89.4$)$ & $<0.01$ \\
\hline Girls & $92.8(92.4$ to 93.2$)$ & 92.3 (91.9 to 92.7$)$ & 92.1 (91.7 to 92.5$)$ & $91.2(90.8$ to 91.6$)$ & $91.6(91.2$ to 92.0$)$ & $<0.01$ \\
\hline \multicolumn{7}{|c|}{ PEFR (\% predicted) ${ }^{*}$} \\
\hline Boys & 88.0 (86.7 to 89.3$)$ & 89.5 (88.0 to 90.9$)$ & 88.7 (87.4 to 90.1$)$ & 89.1 (87.8 to 90.4 ) & 88.7 (87.4 to 90.1$)$ & 0.75 \\
\hline Girls & $91.2(89.5,92.8)$ & $93.3(91.7$ to 94.9$)$ & 93.2 (91.6 to 94.7$)$ & $93.6(92.1$ to 95.2$)$ & $94.7(93.1$ to 96.3$)$ & 0.04 \\
\hline \multicolumn{7}{|c|}{$\mathrm{FEF}_{25-75}(\% \text { predicted })^{*}$} \\
\hline Boys & 94.2 (92.5 to 95.9$)$ & 94.2 (92.4 to 95.9 ) & 94.7 (93.1 to 96.3$)$ & 93.5 (91.8 to 95.1$)$ & 94.6 (92.9 to 96.3$)$ & 0.81 \\
\hline Girls & $98.2(96.5$ to 100.0$)$ & 99.4 (97.7 to 101.2$)$ & $100.6(98.8$ to 102.5$)$ & 99.7 (97.8 to 101.6$)$ & $103.2(101.3$ to 105.1$)$ & \\
\hline \multicolumn{7}{|c|}{ - } \\
\hline Boys & 5.92 (5.51 to 6.37$)$ & 6.32 (5.84 to 6.84 ) & 5.80 (5.41 to 6.23$)$ & $5.70(5.35$ to 6.06$)$ & 5.71 (5.35 to 6.09 ) & 0.21 \\
\hline Girls & $4.81(4.50$ to 5.15$)$ & $4.96(4.67$ to 5.26$)$ & 4.93 (4.63 to 5.24$)$ & 4.95 (4.67 to 5.24$)$ & $4.86(4.59$ to 5.14$)$ & 0.95 \\
\hline \multicolumn{7}{|c|}{ AHR $(\mathrm{DRR}>8.1)^{\star *}$} \\
\hline Boys & 22.7 (19.4 to 26.0$)$ & $23.5(20.1$ to 26.9$)$ & 22.0 (18.6 to 25.4$)$ & 22.1 (18.9 to 25.3$)$ & $21.2(17.9$ to 24.5$)$ & 0.41 \\
\hline Girls & $16.3(13.3$ to 19.3$)$ & $15.1(12.2$ to 18.0$)$ & $15.2(12.4$ to 18.0$)$ & $16.6(13.6$ to 19.6$)$ & $14.8(12.0$ to 17.7$)$ & 0.92 \\
\hline
\end{tabular}

*Results are reported as mean with $95 \%$ confidence intervals.

**Results are reported as prevalence with $95 \%$ confidence intervals.

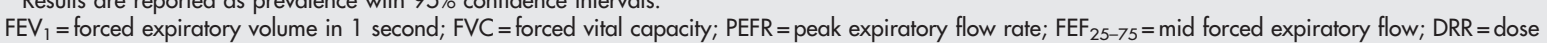
response ratio ( $\%$ fall in $\mathrm{FEV}_{1} /$ dose of histamine $\left.)+3\right) ; \mathrm{AHR}=$ airway hyperresponsiveness. 
was found in Taiwanese girls, ${ }^{3}$ whereas another large study showed this association in men only. ${ }^{9}$ Our study does not confirm this since we found that BMI was not correlated with airway responsiveness, measured by DRR, nor was higher BMI associated with increased prevalence of airway hyperresponsiveness in either boys or girls.

Our study has significant clinical implications. Previous studies have shown higher rates of diagnosed asthma in obese children. $^{2} 3^{10}{ }^{31-33}$ However, without evidence of airway obstruction or airway responsiveness, it is unlikely that these children truly have asthma. It is important to elucidate the true aetiology of symptoms in overweight children. Increasing symptoms with higher weight may be the result of being unfit, worsening asthma, gastro-oesophageal reflux, or sleep disordered breathing. The treatment options for these aetiologies vary markedly. Some may require inhaled or even oral corticosteroids which, if used indiscriminately, may exacerbate the weight problem. Others may be more likely to benefit from a weight loss programme, $\mathrm{H}_{2}$ blockers, or even nasal continuous positive airway pressure.

It is unlikely that a higher BMI is a risk factor for asthma or airway hyperresponsiveness in children, and it is likely that the prevalence of asthma in obese children is the same as in the rest of the population. Obesity and asthma are both significant health problems and must be addressed in both children and adults to optimise lung function and quality of life.

\section{Authors' affiliations}

L M Schachter, C M Salome, Woolcock Institute, University of Sydney, Sydney, NSW 2006, Australia

J K Peat, Clinical Epidemiology Unit, University of Sydney, Department of Paediatrics and Child Health, New Children's Hospital, Westmead, NSW 2145, Australia

L M Schachter, Department of Respiratory Medicine, Austin and Repatriation Medical Centre, Heidelberg, VIC 3084, Australia

\section{REFERENCES}

1 Woolcock AJ, Peat JK. Evidence for the increase in asthma worldwide. Ciba Found Symp 1997;206:122-34, discussion 134-9, 157-9.

2 Gennuso J, Epstein LH, Paluch RA, et al. The relationship between asthma and obesity in urban minority children and adolescents. Arch Pediatr Adolesc Med 1998;152:1197-200

3 Huang SL, Shiao G, Chou P. Association between body mass index and allergy in teenage girls in Taiwan. Clin Exp Allergy 1999;29:323-9.

4 Shaheen SO, Sterne JA, Montgomery SM, et al. Birth weight, body mass index and asthma in young adults. Thorax 1999;54:396-402.

5 Camargo CA Jr, Weiss ST, Zhang S, et al. Prospective study of body mass index, weight change, and risk of adult-onset asthma in women. Arch Intern Med 1999;159:2582-8.

6 Schachter LM, Salome CM, Peat JK, et al. Obesity is a risk for asthma and wheeze but not airway hyperresponsiveness. Thorax 2001;56:4-8.

7 Stenius-Aarniala B, Poussa T, Kvarnstrom J, et al. Immediate and long term effects of weight reduction in obese people with asthma: randomised controlled study. BMJ 2000;320:827-32.
8 Dixon JB, Chapman L, O'Brien P. Marked improvement in asthma after LapBand surgery for morbid obesity. Obes Surg 1999;9:385-9.

9 Chinn S, Jarvis D, Burney P. Relation of bronchial responsiveness to body mass index in the ECRHS. Thorax 2002:57:1028-33.

10 Kaplan TA, Montana E. Exercise-induced bronchospasm in nonasthmatic obese children. Clin Pediatr (Phila) 1993;32:220-5.

11 Jarvis D, Chinn S, Potts J, et al. Association of body mass index with respiratory symptoms and atopy: results from the European Community Respiratory Health Survey. Clin Exp Allergy 2002;32:831-7.

12 Peat JK, van den Berg RH, Green WF, et al. Changing prevalence of asthma in Australian children. BMU 1994;308:1591-6.

13 Peat JK, Toelle BG, Gray EJ, et al. Prevalence and severity of childhood asthma and allergic sensitisation in seven climatic regions of New South Wales. Med J Aust 1995; 163:22-6.

14 Burney PG, Laitinen LA, Perdrizet S, et al. Validity and repeatability of the IUATLD (1984) Bronchial Symptoms Questionnaire: an international comparison. Eur Respir J 1989;2:940-5.

15 Hsu KH, Jenkins DE, Hsi BP, et al. Ventilatory functions of normal children and young adults--Mexican-American, white, and black. I. Spirometry. J Pediatr 1979:95:14-23.

16 Yan K, Salome C, Woolcock AJ. Rapid method for measurement of bronchial responsiveness. Thorax 1983;38:760-5.

17 Daniels SR, Khoury PR, Morrison JA. The utility of body mass index as a measure of body fatness in children and adolescents: differences by race and gender. Pediatrics 1997;99:804-7.

18 White EM, Wilson AC, Greene SA, et al. Body mass index centile charts to assess fatness of British children. Arch Dis Child 1995;72:38-41.

19 Cronk CE, Roche AF. Race- and sex-specific reference data for triceps and subscapular skinfolds and weight/stature. Am J Clin Nutr 1982;35:347-54.

20 Peat JK, Salome CM, Xuan W. On adjusting measurements of airway responsiveness for lung size and airway caliber. Am J Respir Crit Care Med 1996:154(4 Pt 1):870-5.

21 Mulligan J. Standard definition of child overweight and obesity worldwide. Body mass index is harder to interpret in children than adults. BMJ 2000;321:1159.

22 Cole TJ, Bellizzi MC, Flegal KM, et al. Establishing a standard definition for child overweight and obesity worldwide: international survey. BMJ 2000;320:1240-3.

23 Reilly JJ, Dorosty AR, Emmett PM. Identification of the obese child: adequacy of the body mass index for clinical practice and epidemiology. Int J Obes Relat Metab Disord 2000;24:1623-7.

24 Magarey AM, Daniels LA, Boulton TJ. Prevalence of overweight and obesity in Australian children and adolescents: reassessment of 1985 and 1995 data against new standard international definitions. Med J Aust 2001;174:561-4.

25 Castell DO. Obesity and gastro-oesophageal reflux: is there a relationship? Eur J Gastroenterol Hepatol 1996;8:625-6.

26 Grunstein RR, Wilcox I. Sleep-disordered breathing and obesity. Baillieres Clin Endocrinol Metab 1994:8:601-28.

27 Pelosi P, Croci M, Ravagnan I, et al. The effects of body mass on lung volumes, respiratory mechanics, and gas exchange during general anesthesia. Anesth Analg 1998;87:654-60.

28 Fredberg JJ, Inouye DS, Mijailovich SM, et al. Perturbed equilibrium of myosin binding in airway smooth muscle and its implications in bronchospasm. Am J Respir Crit Care Med 1999;159:959-67.

29 Ding DJ, Martin JG, Macklem PT. Effects of lung volume on maximal methacholine-induced bronchoconstriction in normal humans. J Appl Physiol 1987:62:1324-30

30 Woolcock AJ. Use of corticosteroids in treatment of patients with asthma $J$ Allergy Clin Immunol 1989;84:975-8.

31 Luder E, Melnik TA, DiMaio M. Association of being overweight with greater asthma symptoms in inner city black and Hispanic children. J Pediatr 1998; 132:699-703.

32 Unger R, Kreeger L, Christoffel KK. Childhood obesity. Medical and familial correlates and age of onset. Clin Pediatr (Phila) 1990;29:368-73.

33 Figueroa-Munoz JI, Chinn S, Rona RJ. Association between obesity and asthma in 4-11 year old children in the UK. Thorax 2001;56:133-7. 